\title{
The Male Reproductive Cycle of the Spotted Toad-Headed Agama, Phrynocephalus maculatus, in Iran
}

\author{
Soheila Rahmani and Vida Hojati \\ Department of Biology, Damghan Branch, Islamic Azad University, Damghan 36716 39998, Iran \\ Correspondence should be addressed to Vida Hojati; vida.hojati@gmail.com
}

Received 9 September 2015; Accepted 2 November 2015

Academic Editor: Marco Cucco

Copyright (C) 2015 S. Rahmani and V. Hojati. This is an open access article distributed under the Creative Commons Attribution License, which permits unrestricted use, distribution, and reproduction in any medium, provided the original work is properly cited.

The spotted toad-headed agama, Phrynocephalus maculatus, distributed in the central and southeastern arid regions of Iran, belongs to the Agamidae family. In this research, the male reproductive cycle of this species was studied from 5 April to 5 August, 2013. Totally, 40 adult males were collected at midday from southern deserts of Damghan County, located in Semnan Province of Iran. Testes were removed and processed for morphometric and histological studies. The spermatogenic cycle begins from early April, mating occurs in mid-May, and it ends in August. Maximum reproductive activity occurs in early June and reduces from early July and ends in August. The numbers of seminal vesicles were 33-127 and their diameter varied between 69.0 and 258.3 microns. The diameter of tunica albuginea varied between 3.0 and 8.1 microns. The diameter of germinal layer varied between 10.0 and 110.0 microns. There were significant differences in macroscopic and microscopic testicular characters between months. Also, there were no significant differences in the testicular and hemipenal characters between the left side and the right side of body. Since spermatogenesis occurs from April through August, $P$. maculatus follows an associated reproductive cycle typical for temperate species.

\section{Introduction}

The structure of testis and spermatogenesis of lizards have similar features but there are some new data in the species studied. Lizards of the genus Phrynocephalus, distributed from northwestern China to Turkey, belong to the Agamidae family and they are major components of the central Asian desert fauna [1]. This agama inhabits desert regions, desiring harder sandy surfaces [2]. The activity of this species occurs during all but the hottest hours of the day, scurrying across the sand and in the hunt for its insect prey. Toad-headed lizards of the genus Phrynocephalus are reproductively bimodal (oviparous and viviparous) with all viviparous species restricted to the Qinghai-Tibet Plateau of China and adjacent regions [3-5]. The spotted toadheaded agama, $P$. maculatus, is an oviparous lizard capable of sinking rapidly into the sand through vibrating the body in a process called "shimmy burial," and this behavior is used to escape from predators or create a nocturnal shelter [6]. The subspecies, black-tailed toad-headed agama, P. maculatus
Anderson, 1872, are distributed on the Central Plateau of Iran, at elevations between 500 and $3000 \mathrm{~m}$, east through southern Afghanistan and Baluchistan, and extending into Nushki, Pakistan [7]. Along with many other species of reptiles in the Middle East region, P. maculatus is a fairly understudied species. This species has yet to be assessed by the IUCN. Consequently, it is currently unclear whether there are many major threats to the species or not [8]. A preliminary study on the biology of this species in Iran was performed and useful information about this species has been presented for the first time [9]. This research was conducted to characterize the spermatogenic cycle of this species in Iran.

\section{Materials and Methods}

All specimens were collected from four stations, Hassan Abad, Saleh Abad, Alian, and Yazdan Abad villages, located in the south of Damghan County, Semnan Province $\left(54^{\circ} 19^{\prime} \mathrm{E}\right.$, $35^{\circ} 55^{\prime} \mathrm{N}$ ). Damghan is situated $1170 \mathrm{~m}$ above sea level north 
of the Central Kavir Desert. The annual average temperature is $17.2^{\circ} \mathrm{C}$. The study area is composed of alkaline saline soils containing clay and sand. The dominant plant species are Tamarix sp., Salsola sp., Alhaji sp., Peganum sp., Atriplex sp., and Astragalus sp. Sampling was conducted periodically every month during the activity period of this species from 5 April to 5 August, 2013. All specimens were collected by hand from $9 \mathrm{AM}$ to $4 \mathrm{PM}$. In total, 40 mature males were captured (eight specimens per sampling period). The specimens were transferred alive to the laboratory following guidelines for the care and use of laboratory animals approved by the Animal Care and Use Committee of Damghan Branch, Islamic Azad University, Iran. The following measurements were taken: W (body weight), SVL (Snout-Vent Length), LCD (Tail Length), HL (Head Length), HW (Head Width), RTL (Right Testis Length), LTL (Left Testis Length), RTWi (Right Testis Width), LTWi (Left Testis Width), RTW (Right Testis Weight), LTW (Left Testis Weight), RTV (Right Testis Volume), LTV (Left Testis Volume), RTAD (Right Tunica Albuginea Diameter), LTAD (Left Tunica Albuginea Diameter), RSVN (Right Seminal Vesicles Number), LSVN (Left Seminal Vesicles Number), RSVD (Right Seminal Vesicle Diameter), LSVD (Left Seminal Vesicle Diameter), RGLD (Right Germinal Layer Diameter), LGLD (Left Germinal Layer Diameter), RLD (Right Lumen Diameter), LLD (Left Lumen Diameter), RSgN (Right Spermatogonia Number), LSgN (Left Spermatogonia Number), RSpN (Right Spermatocytes Number), LSpN (Left Spermatocytes Number), RStN (Right Spermatids Number), LStN (Left Spermatids Number), RSN (Right Sperms Number), LSN (Left Sperms Number), gonadal index (GI = gonadal weight/body weight $\times$ 100), RHpL (Right Hemipenis Length), LHpL (Left Hemipenis Length), RHpWi (Right Hemipenis Width), and LHpWi (Left Hemipenis Width). Length, width, and diameter values were measured by dial caliper with an accuracy of $0.02 \mathrm{~mm}$. Weight was measured by scale with an accuracy of $0.001 \mathrm{~g}$. Volume of the testis was calculated by using the formula for the volume of an ellipsoid: $4 / 3 \pi a b^{2}$, where $a=1 / 2$ the longest axis and $b=1 / 2$ the shortest axis. Gonads, once removed, were measured for metric and meristic studies. Weight, diameter (length and width), and volume values were measured for the right testis and left testis separately. After fixing the testes in $10 \%$ formalin, tissues were dehydrated, cleared in xylene, infiltrated with paraffin, embedded and sectioned, and stained with hematoxylin and eosin following standard histological protocols. The sections were studied by light microscopy at 400x magnification. Photographs were prepared by digital camera, while the data was analyzed by SPSS 18 software and one-way ANOVA and Tukey's test.

\section{Results}

The species hibernate from October to March. Early spermiogenesis starts in March and continues from April to July. The descriptive statistics of characters in P. maculatus are shown in Table 1 . The mean body weight, Snout-Vent Length, Tail Length, Head Length, and Head Width of males were $7.4 \mathrm{~g}, 59.6 \mathrm{~mm}, 90.3 \mathrm{~mm}, 13.0 \mathrm{~mm}$, and $12.6 \mathrm{~mm}$, respectively.
The smallest SVL was $50.9 \mathrm{~mm}$, while the largest one was $67.7 \mathrm{~mm}$. There was no significant difference in body size characters including $W$, SVL, LCD, HL, and HW through different months. The mean weight, length, width, and volume of right testes were $0.053 \mathrm{~g}, 5.15 \mathrm{~mm}, 3.7 \mathrm{~mm}$, and $47.1 \mathrm{~mm}^{3}$, respectively. The mean weight, length, width, and volume of left testes were $0.053 \mathrm{~g}, 5.5 \mathrm{~mm}, 3.6 \mathrm{~mm}$, and $48.6 \mathrm{~mm}^{3}$, respectively. The mean numbers of seminiferous tubules in right and left testes were 86.9 and 76.3, respectively. The mean diameters of seminiferous tubules in right and left testes were 169.3 and 175.9 microns, respectively. The mean diameters of the tunica albuginea, germinal layer, and lumen were 5.6, 65.1, and 61.3 microns in right testes and $5.6,65.2$, and 57.5 microns in left testes, respectively. The mean numbers of spermatogonia, spermatocytes, spermatids, and sperms were $140.4,254.3,80.6$, and 385.6 in right testes and 123.8, 283.0, 70.9, and 456.4 in left testes, respectively. Observation of the large numbers of mature sperms in the tubules in early April shows that the spermatogenesis starts from March. The Sertoli cells, spermatogonia, and spermatocytes were observed in the seminiferous tubules during the reproductive season from April to August. The spermatids were observed in the germinal layer from April to early August, but their number was reduced after June. The spermatozoids were abundant in the lumen of tubules during May and June and there were no spermatozoids after July. Figures 1 and 2 show the histological sections of seminiferous tubules of $P$. maculatus in different months. The maximum and minimum diameter, weight, and volume of testes were observed in June and August, respectively. The maximum and minimum heights of germinal epithelium were observed during April and August, respectively. Maximum size of tubule diameter was observed in May. Tunica albuginea diameter reached its maximum and minimum sizes in April and August, respectively. Lumen diameter increased in July and August. The maximum level of sperm production was in June (Figure 3). The gonadal index (GI) increased from April to June and decreased from July to August (Figure 4). There were significant differences in macroscopic and microscopic testicular characters between months (Table 1). There were no significant differences in the testicular and hemipenal characters between the left side and the right side of body (paired $t$-test, $P>0.05$ in all cases). One pair of light pink hemipenes is located at the base of the cloaca (Figure 5). The mean length and width of right hemipenis were 5.7 and $2.5 \mathrm{~mm}$ and those of the left side were 5.1 and $2.4 \mathrm{~mm}$, respectively. There were significant differences in hemipenal characters between months (Table 1). The maximum size of hemipenes was observed in June, while the minimum size was observed in August.

\section{Discussion}

Seasonal changes in the histological morphology of the testes of $P$. maculatus were observed. The reproduction of $P$. maculatus occurs from spring to early summer every year, showing significant seasonal circle. The animal activity began in early April but spermatogenic cycle started at the end of 
TABle 1: Descriptive statistics of macroscopic characters in Phrynocephalus maculatus $(N=40)$.

\begin{tabular}{|c|c|c|c|c|c|}
\hline Characters & Minimum & Maximum & Mean \pm std. error & Std. deviation & $p$ value \\
\hline$W(\mathrm{~g})$ & 4.890 & 9.890 & $7.494 \pm 0.211$ & 1.33 & 0.078 \\
\hline SVL (mm) & 50.90 & 67.70 & $59.67 \pm 0.65$ & 4.14 & 0.069 \\
\hline $\mathrm{LCD}(\mathrm{mm})$ & 73.00 & 103.76 & $90.37 \pm 0.89$ & 5.63 & 0.832 \\
\hline $\mathrm{HL}(\mathrm{mm})$ & 10.17 & 15.90 & $13.06 \pm 0.25$ & 1.58 & 0.173 \\
\hline $\mathrm{HW}(\mathrm{mm})$ & 11.59 & 13.98 & $12.62 \pm 0.07$ & 0.44 & 0.065 \\
\hline RTW (g) & 0.012 & 0.115 & $0.053 \pm 0.005$ & 0.033 & 0.000 \\
\hline LTW (g) & 0.010 & 0.113 & $0.053 \pm 0.005$ & 0.036 & 0.000 \\
\hline RTL (mm) & 2.20 & 6.85 & $5.15 \pm 0.23$ & 1.46 & 0.000 \\
\hline LTL (mm) & 2.90 & 7.24 & $5.54 \pm 0.26$ & 1.65 & 0.000 \\
\hline RTWi (mm) & 1.77 & 5.10 & $3.71 \pm 0.16$ & 1.03 & 0.000 \\
\hline LTWi (mm) & 1.81 & 5.34 & $3.64 \pm 0.15$ & 1.00 & 0.000 \\
\hline $\operatorname{RTV}\left(\mathrm{mm}^{3}\right)$ & 4.26 & 80.88 & $47.15 \pm 4.71$ & 29.79 & 0.000 \\
\hline $\operatorname{LTV}\left(\mathrm{mm}^{3}\right)$ & 4.32 & 99.40 & $48.67 \pm 5.14$ & 32.53 & 0.000 \\
\hline RHpL (mm) & 4.60 & 7.49 & $5.72 \pm 0.11$ & 0.71 & 0.000 \\
\hline LHpL (mm) & 2.90 & 6.91 & $5.19 \pm 0.16$ & 1.04 & 0.000 \\
\hline RHpWi (mm) & 2.16 & 3.10 & $2.58 \pm 0.03$ & 0.23 & 0.000 \\
\hline LHpWi (mm) & 1.80 & 3.00 & $2.43 \pm 0.04$ & 0.30 & 0.000 \\
\hline GI & 0.136 & 1.618 & $0.772 \pm 0.08$ & 0.50 & 0.000 \\
\hline $\operatorname{RTAD}(\mu)$ & 4.100 & 7.800 & $5.67 \pm 0.19$ & 1.24 & 0.000 \\
\hline $\operatorname{LTAD}(\mu)$ & 3.00 & 8.10 & $5.65 \pm 0.28$ & 1.79 & 0.000 \\
\hline RSVN & 40.00 & 127.00 & $86.95 \pm 4.23$ & 26.75 & 0.000 \\
\hline LSVN & 33.00 & 99.00 & $76.30 \pm 3.20$ & 20.24 & 0.000 \\
\hline $\operatorname{RSVD}(\mu)$ & 69.00 & 241.70 & $169.35 \pm 10.87$ & 68.78 & 0.000 \\
\hline $\operatorname{LSVD}(\mu)$ & 90.00 & 258.30 & $175.92 \pm 9.63$ & 60.94 & 0.000 \\
\hline $\operatorname{RGLD}(\mu)$ & 10.00 & 110.00 & $65.18 \pm 6.38$ & 40.38 & 0.000 \\
\hline $\operatorname{LGLD}(\mu)$ & 12.00 & 107.50 & $65.26 \pm 5.81$ & 36.77 & 0.000 \\
\hline $\operatorname{RLD}(\mu)$ & 40.00 & 89.00 & $61.33 \pm 2.27$ & 14.41 & 0.000 \\
\hline $\operatorname{LLD}(\mu)$ & 40.00 & 81.00 & $57.56 \pm 1.95$ & 12.38 & 0.000 \\
\hline $\mathrm{RSgN}$ & 12.00 & 284.00 & $140.45 \pm 17.37$ & 109.89 & 0.000 \\
\hline LSgN & 23.00 & 256.00 & $123.87 \pm 14.16$ & 89.58 & 0.000 \\
\hline $\mathrm{RSpN}$ & 13.00 & 587.00 & $254.35 \pm 32.49$ & 205.50 & 0.000 \\
\hline $\mathrm{LSpN}$ & 13.00 & 594.00 & $283.00 \pm 35.84$ & 226.68 & 0.000 \\
\hline RStN & 26.00 & 203.00 & $80.67 \pm 9.65$ & 61.07 & 0.000 \\
\hline LStN & 13.00 & 132.00 & $70.90 \pm 6.13$ & 38.77 & 0.000 \\
\hline RSN & 31.00 & 716.00 & $385.65 \pm 36.98$ & 233.90 & 0.000 \\
\hline LSN & 24.00 & 919.00 & $456.47 \pm 47.19$ & 298.50 & 0.000 \\
\hline
\end{tabular}

winter. Spermatogenesis reached its peak in early May and ended between July and August. Similar observations were reported in Phrynocephalus przewalskii [10]. The weight and the volume of the testes of $P$. przewalskii were at maximum size in May and regularly decreased in June changing into smallest size and there were no sperms in seminiferous tubules in July [10]. The weight and the volume of testes gradually increased in August. In mid-October before lizards began to hibernate their testes were similar to those in April [10]. In P. maculatus similar to $P$. przewalskii, testes were histologically in full breeding condition from April to June. During spermatogenic stage, there are some changes which occur in germ cells. In Phrynocephalus forsythia, with the maturation of the sperm, the sizes of germ cell become smaller than those of early stages, with a large typical subspherical nucleus with heterochromatin, and then sperm cells move to the lumen of seminiferous tubules [11].

Reproductive cycles of two sympatric lizards, Phrynocephalus reticulatus and $P$. helioscopus, were studied in Southern Uzbekistan [12]. Both species consist of spring active period including mating, ovulation, and egg deposition, summer regressive phase or summer hibernation, autumn period of recrudescence of gonadal activity, and winter hibernation. During the period of autumn recrudescence, spermatogenesis is observed in both species. This process is shown by release of the spermatozoa into tubules and enough development of epididymis and by activation of sexual segment in males of $P$. helioscopus but not in males 


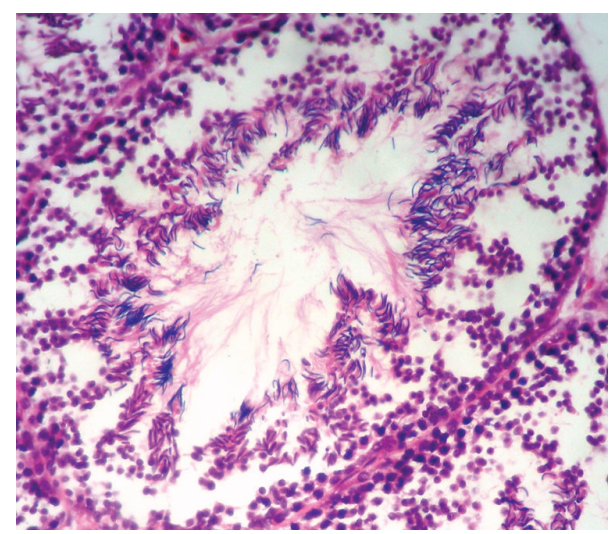

FIGURE 1: Seminiferous tubules of Phrynocephalus maculatus in May.

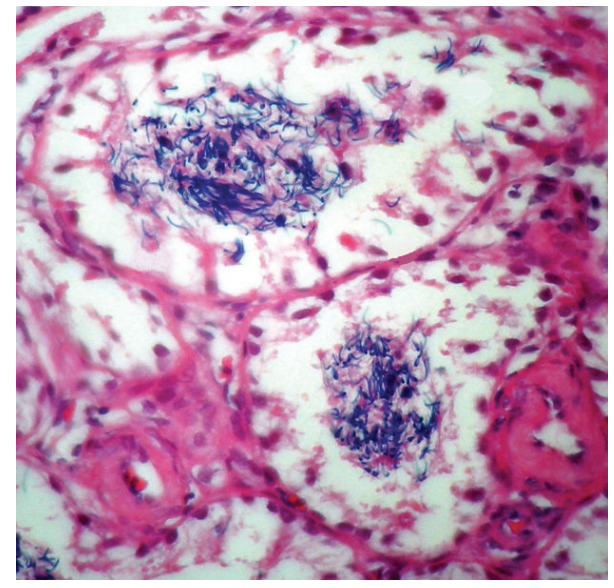

Figure 2: Seminiferous tubules of Phrynocephalus maculatus in June.

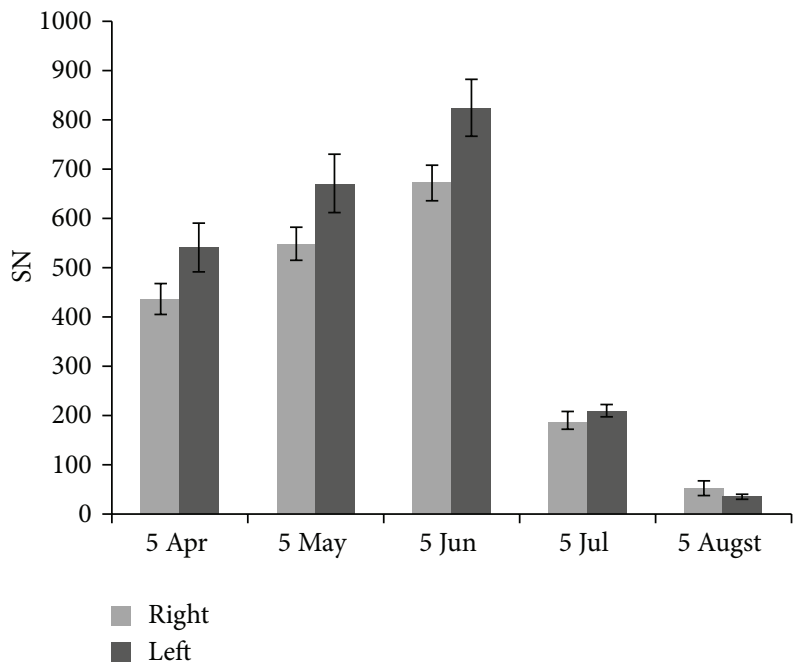

FIGURE 3: Mean of sperm number (SN) of Phrynocephalus maculatus from April to August.

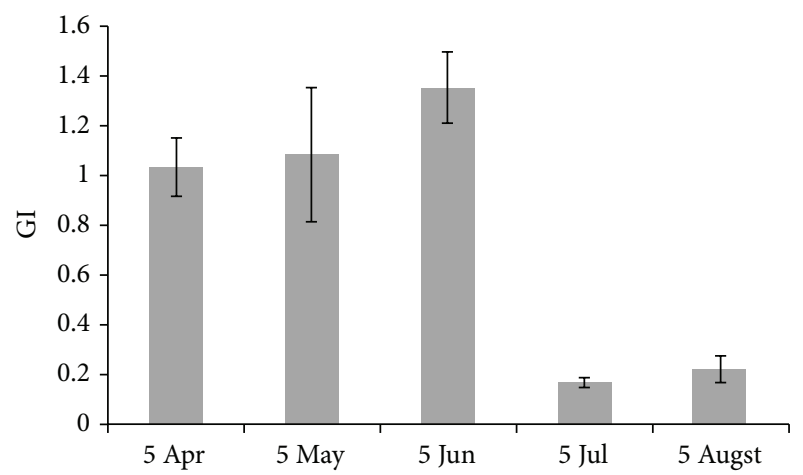

FIgure 4: Mean of gonadal index (GI) of Phrynocephalus maculatus from April to August.

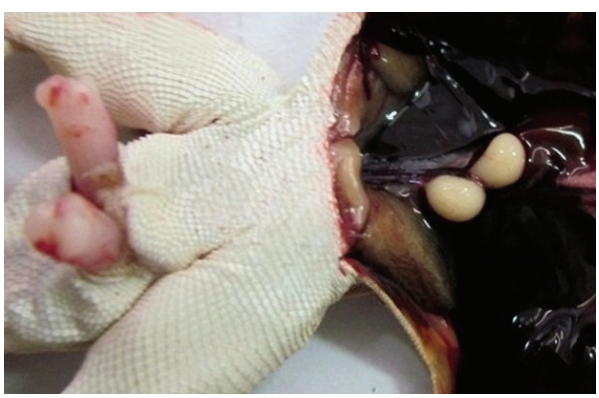

Figure 5: Hemipenis and testis of Phrynocephalus maculatus.

of $P$. reticulatus [12]. The combination of data from the study of hatchling morphology of five Phrynocephalus species including $P$. albolineatus, $P$. axillaris, $P$. grumgrzimailoi, $P$. helioscopus, and P. przewalskii [13] and previous study on $P$. frontalis and $P$. versicolor [14] showed that any Phrynocephalus species may have its unique position along the axis defined by hatchling morphology [13]. Data from the study of $P$. frontalis, $P$. przewalskii, and $P$. versicolor consistently show that incubation length decreases at an ever decreasing rate as temperature increases across the range where successful embryonic development can occur [14, 15]. The spermatogenic cycles of other lizards of Iran have been studied and have shown similar results [16-18]. All lizards of the study area hibernated from October or November to March. In $P$. maculatus, most of testicular characters were observed in minimum size in August. The other sympatric lizards, Teratoscincus bedriagai and Tenuidactylus caspius, have been studied in the study area. They start their reproductive activities earlier than other studied species in Iran. Gonadal index of Tenuidactylus caspius increased from September to November and the peak of spermatogenesis was in May and June. The gonadal index of $P$. maculates increased during spring because the testis weight increased after hibernation and body weight decreased during hibernation. Gonadal index decreased in summer because the testis weight was reduced as a result of the high reproductive activity in spring. Probably, GI will increase after August because the testis weight increases again due to entering the silent and 
regenerative phase of spermatogenic cycle. The spermatogenic cycles of other agamids of Iran such as Paralaudakia caucasia, Trapelus agilis, Trapelus lessonae, Laudakia nupta, and Phrynocephalus scutellatus have been studied and similar results have been obtained [16, 19-22]. Moreover, the female reproductive cycle of $P$. maculatus was studied in this area and it showed the synchronization between the ovarian and testicular activities [23]. Maximum reproductive activity occurs in May and early June and reduces from early July and ends in August. Females lay 2-3 eggs per clutch with the possibility of producing a secondary clutch later in the season [23]. Since spermatogenesis of P. maculatus occurs from April to July, this species follows a seasonal reproductive cycle with associate type.

\section{Conflict of Interests}

The authors declare that there is no conflict of interests regarding the publication of this paper.

\section{Acknowledgments}

Collecting permits and legal requirements were prepared by Department of Environment of Semnan Province of Iran. The authors wish to thank Reza Babaei Savasari for his help in sampling.

\section{References}

[1] W. Zhao, N. Yu, Y. Wang, W. Ji, and N. Liu, "Female reproductive cycles of Phrynocephalus przewalskii (Lacertilia: Agamidae) in the Tengger Desert, China," Asian Herpetological Research, vol. 2, no. 1, pp. 30-35, 2011.

[2] P. Hellyer and S. Aspinall, The Emirates: A Natural History, Trident Press, London, UK, 2005.

[3] K. T. Zhao, "Phrynocephalus Kaup," in Fauna Sinica, Reptilia (Squamata: Lacertilia), E. M. Zhao, K. T. Zhao, and K. Y. Zhou, Eds., vol. 2, pp. 151-193, Science Press, Beijing, China, 1999.

[4] A. V. Barabanov and N. B. Ananjeva, "Catalogue of the available scientific species group names for lizards of the genus Phrynocephalus Kaup, 1825 (Reptilia, Sauria, Agamidae)," Zootaxa, vol. 1399, pp. 1-57, 2007.

[5] D. W. A. Noble, Y. Qi, and J. Fu, "Species delineation using Bayesian model-based assignment tests: a case study using Chinese toad-headed agamas (genus Phrynocephalus)," BMC Evolutionary Biology, vol. 10, no. 1, article 197, 2010.

[6] E. Firouz, The Complete Fauna of Iran, I.B. Tauris Publishers, London, UK, 2005.

[7] S. C. Anderson, The Lizards of Iran, Society for the Study of Amphibians and Reptiles, Ithaca, NY, USA, 1999.

[8] A. Alsharhan, R. J. Perry, and Abu Dhabi Department of Environment, Terrestrial Environment of Abu Dhabi Emirate, Environment Agency, Abu Dhabi, United Arab Emirates, 2008.

[9] V. Hojati, M. Malekmohammadi, and S. Rahmani, "A preliminary study on the biology of the black-tailed toad agama, Phrynocephalus maculatus maculatus in Iran," CIBTech Journal of Zoology, vol. 3, no. 3, pp. 60-67, 2014.

[10] N. Liu, Q. Chen, and X. Xie, "Reproductive ecology of Phrynocephalus przewalskii," Acta Ecologica Sinica, vol. 16, no. 3, pp. 276-282, 1996.
[11] O. Abliz and L. Yang, "Microstructural observation on the testis of Phrynocephalus forsythi (Anderson)," Journal of Xinjiang University (Natural Science Edition), vol. 16, no. 2, pp. 52-57, 1999.

[12] S. A. Ivanova, "Reproductive cycles of Phrynocephalus reticulatus and Phrynocephalus helioscopus Sauria, Agamidae," Zoologicheskii Zhurnal, Iyul, vol. 727, pp. 116-130, 1993.

[13] Z. Wang, L. Ma, M. Shao, and X. Ji, "Differences in incubation length and hatchling morphology among five species of oviparous Phrynocephalus lizards (Agamidae) from China," Asian Herpetological Research, vol. 4, no. 4, pp. 225-232, 2013.

[14] Y.-F. Qu, J.-F. Gao, L.-X. Mao, and X. Ji, "Sexual dimorphism and female reproduction in two sympatric toad-headed lizards, Phrynocephalus frontalis and P. versicolor (Agamidae)," Animal Biology, vol. 61, no. 2, pp. 139-151, 2011.

[15] X. L. Tang, F. Yue, M. Ma, N. B. Wang, J. Z. He, and Q. Chen, "Effects of thermal and hydric conditions on egg incubation and hatchling phenotypes in two Phrynocephalus lizards," Asian Herpetological Research, vol. 3, no. 3, pp. 184-191, 2012.

[16] F. Torki, "Spermatogenesis in the agama Trapelus lessonae (Agamidae: Reptilia) in the Central Zagros Mountains, Iran," Zoology in the Middle East, vol. 38, pp. 21-28, 2006.

[17] V. Hojati, K. Parivar, E. Rastegar-Pouyani, and A. Shiravi, "Observations on the spermatogenic cycle of the caspian benttoed gecko, Cyrtopodion caspium, in Iran (Sauria: Gekkonidae)," Zoology in the Middle East, vol. 59, no. 1, pp. 20-29, 2013.

[18] A. Choopani, V. Hojati, and A. Shiravi, "The spermatogenic cycle of the green-bellied lizard, Darevskia chlorogaster (Sauria: Lacertidae) in Northern Iran," CIBTech Journal of Zoology, vol. 3, no. 1, pp. 62-68, 2014.

[19] E. Rastegar-Pouyani, The biosystematics and reproductive biology of some species of Aagamidae Family in Semnan Province of Iran [M.S. thesis in Developmental Biology], Tarbiat Moallem University, Tehran, Iran, 1997 (Persian).

[20] M. Yazdanpanahi, The study of lizards' fauna in Shahrood [M.S. thesis in Animal Biosystematics], Shahid Beheshti University, Tehran, Iran, 2000 (Persian).

[21] F. Torki, "The role of hibernation on the testicular cycle and its activation in Trapelus lessonae (Reptilia: Agamidae) during dormancy," Salamandra, vol. 43, no. 4, pp. 245-248, 2007.

[22] S. Eris, The biosystematics and reproductive biology of some lizards species of Iran [Ph.D. thesis in Developmental Biology], Sciense and Research Branch, Islamic Azad University, Tehran, Iran, 2007, 2007 (Persian).

[23] M. Malekmohammadi-Kalahroudi and V. Hojati, "The female reproductive cycle of the spotted toad-headed agama, Phrynocephalus maculatus (Sauria: Agamidae) in Iran," Iranian Journal of Animal Biosystematics, vol. 10, no. 2, pp. 29-38, 2014. 

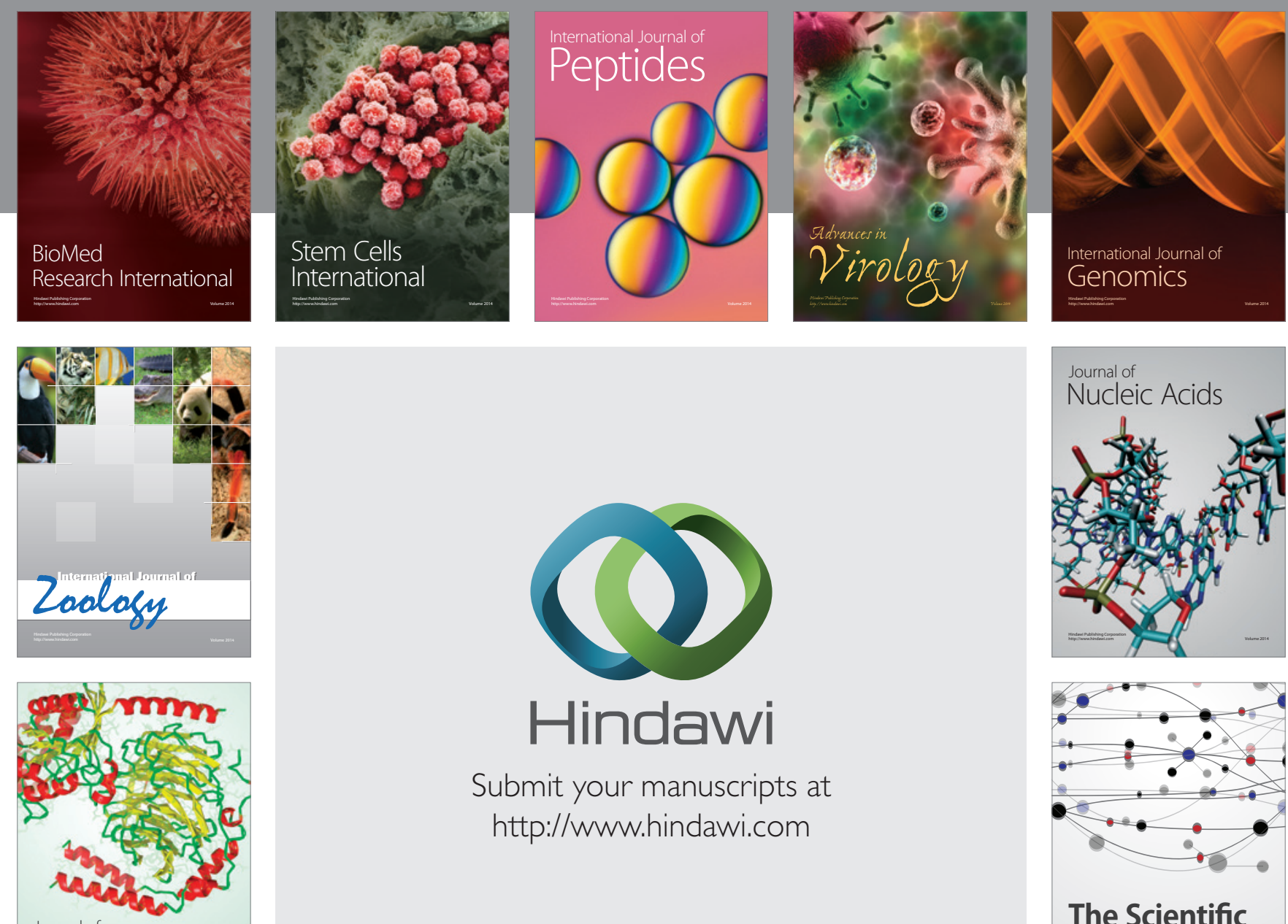

Submit your manuscripts at

http://www.hindawi.com

Journal of
Signal Transduction
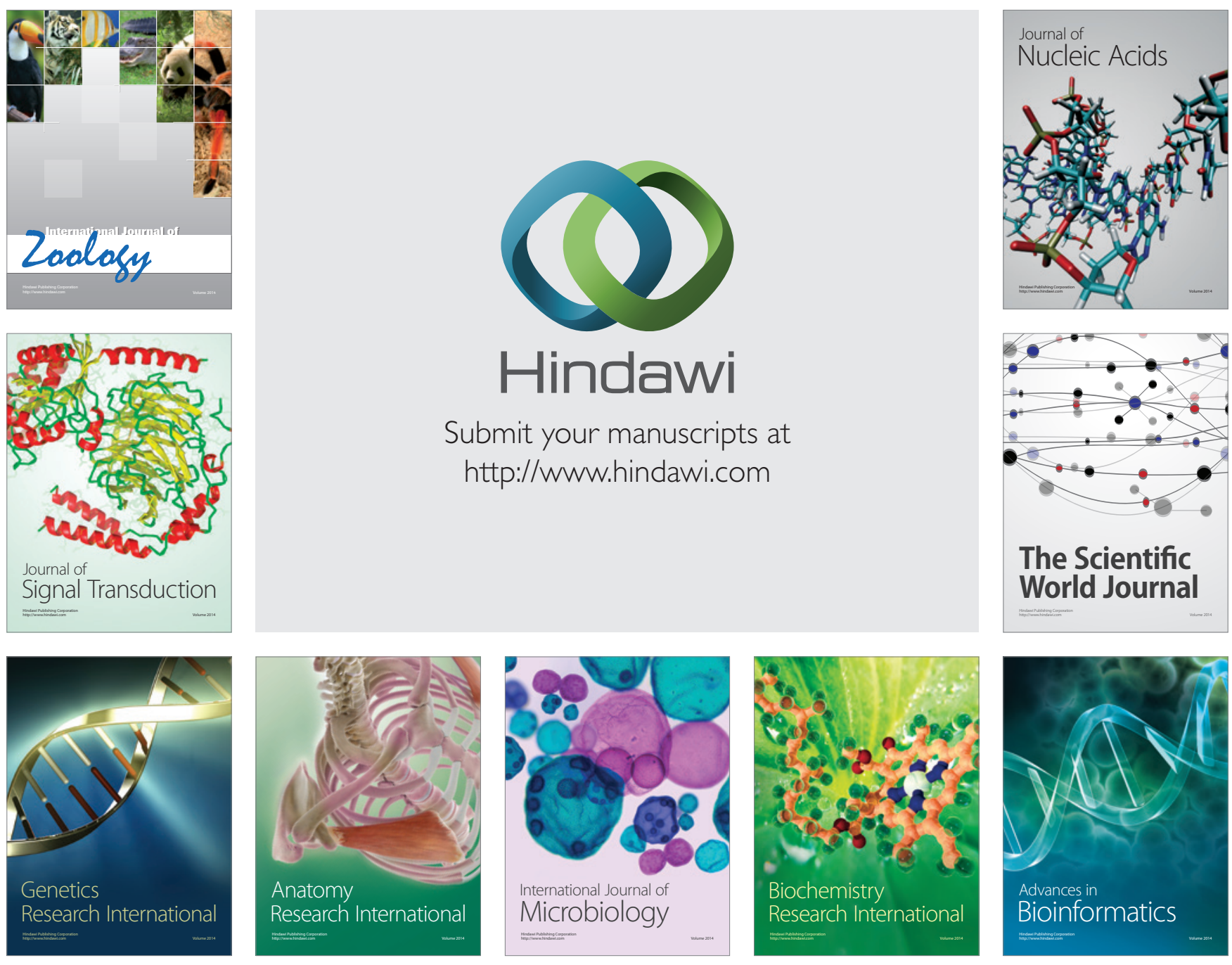

The Scientific World Journal
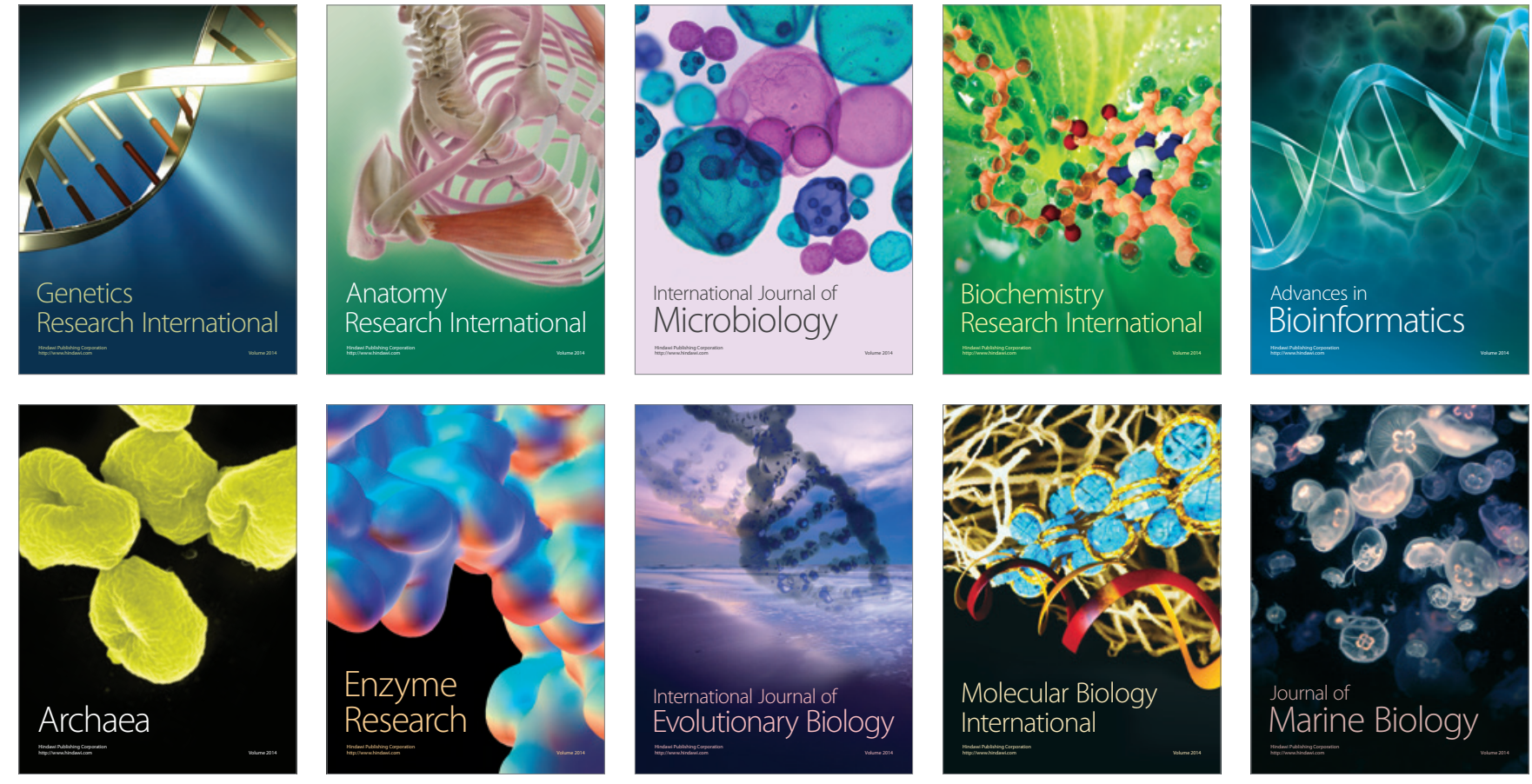